\title{
Processo de formação de estratégias internacionais na fruticultura brasileira: uma abordagem integrada
}

\author{
Training procedure of international strategies in brazilian fruticultura: an \\ integrated approach
}

\author{
Brigitte Renata Bezerra de Oliveira ${ }^{1}$ \\ Walter Fernando Araújo de Moraes ${ }^{2}$ \\ Érica Piros Kovacs ${ }^{3}$ \\ Rafael Lucian ${ }^{4}$
}

\section{Resumo}

Este artigo tem como objetivo analisar as características do processo de formação de estratégias internacionais do Grupo Fruitfort, no período de 1982 a 2006, à luz das teorias de Uppsala, do modelo Diamante e da resource-based view, associadas à mudança estratégica. A pesquisa caracteriza-se como estudo de caso qualitativo, do tipo exploratório e analítico, de cunho retrospectivo. A coleta de dados deu-se mediante a realização de entrevistas semi-estruturadas, de pesquisa documental e da observação não-participante. Descrevem-se as estratégias internacionais adotadas pela empresa e analisa-se sua aproximação com os conceitos apregoados pelos modelos teóricos, numa abordagem longitudinal. Evidenciam-se indícios da associação concomitante entre os modelos de internacionalização, considerando que nenhum, isoladamente, foi capaz de explicar como o processo de formação de estratégias internacionais ocorreu na empresa, variando apenas o grau de proximidade dos seus conceitos principais. As dimensões mais relevantes de Uppsala foram a aprendizagem, as networks e o gradualismo. Três vértices do Modelo Diamante, a saber: condições dos fatores, indústrias correlatas e a rivalidade entre as empresas foram decisivos a empresa. $A$ liderança empreendedora e a cultura organizacional apresentam-se como o seu recurso competitivo de maior expressão.

Palavras-chave: internacionalização; modelo Diamante; Uppsala; RBV.

\section{Abstract}

This article aims to analyze the characteristics of the process of formation of international strategies of Fruitfort Group in the period from 1982 to 2006, in the light of the theories of Uppsala, the Diamond Model and Resource-Based View associated with the strategic shift. The research is characterized as a qualitative exploratory case study. The data collection took place through the implementation of semi-structured interviews, documentary research and non-participant observation. The work describes the international strategies adopted by the company and looks up its convergence with the theoretical models, in a longitudinal approach. A concomitant association between models of internationalization is appointed, given the fact that no individual was able to explain how the process of formation of international strategies occurred in the company, varying only the degree of convergence of its main concepts. The most relevant dimensions of Uppsala were learning, the networks and gradualism. There are three elements of Diamond Model: factor conditions, related industries and rivalry between the companies which were all decisive for the company. The

\footnotetext{
${ }^{1}$ Mestre em Administração, Programa de Pós-Graduação em Administração (PROPAD), da Universidade Federal de Pernambuco -PROPAD/UFPE. Professora Assistente da Universidade Federal do Vale do São Francisco - UNIVASF - Colegiado de Administração - Av. José de Sá Maniçoba, s/n, Centro, PetrolinaPernambuco - Brasil. CEP: 56304-917. E-mail: renata.oliveira@univasf.edu.br

2 Ph.D. em Administração, University of Manchester Institute of Science and Technology, Inglaterra. Professor Titular, Departamento de Ciências Administrativa da Universidade Federal de Pernambuco - UFPE. Endereço: Av. dos Economistas, s/n, 1o. andar, Sala D4, Cidade Universitária, RecifePernambuco - Brasil - CEP: 50670-901. E-mail: walter@fbv.br

3 Doutoranda em Administração, Programa de Pós-Graduação em Administração (PROPAD), da Universidade Federal de Pernambuco -PROPAD/UFPE. Endereço: Av. dos Economistas, s/n, 10. andar, Sala D4, Cidade Universitária, Recife-Pernambuco - Brasil - CEP: 50670-901. E-mail: ericapk@hotmail.com 4 Mestre e Doutorando em Administração, Programa de Pós-Graduação em Administração (PROPAD), da Universidade Federal de Pernambuco PROPAD/UFPE. Endereço: Av. dos Economistas, s/n, 10. andar, Sala D4, Cidade Universitária, Recife-Pernambuco - Brasil - CEP: 50670-901. E-mail: lucian@terra.com.br
}

Artigo submetido em setembro e aceito em novembro de 2008 
entrepreneurial leadership and organizational culture appeared as the competitive resources with greater expression.

Keywords: internationalization; Diamond Model; Uppsala; RBV.

\section{Introdução}

O Brasil é reconhecidamente um país competitivo no mercado internacional, no âmbito do agronegócio, segundo o Ministério do Desenvolvimento (BRASIL, 2007). As exportações brasileiras desse setor alcançaram, no período de dezembro de 2005 a novembro de 2006, US\$48,9 bilhões (quarenta e oito bilhões e novecentos milhões de dólares), 14\% acima do valor negociado no mesmo período entre 2004 e 2005. Isso representa 36\% de todas as exportações brasileiras. Mesmo com o aumento de $29 \%$ nas importações, perfazendo um total de US\$6,49 bilhões (seis bilhões e quatrocentos e noventa milhões de dólares), o superávit comercial acumulado no período ultrapassou em US $\$ 42,4$ bilhões (quarenta e dois bilhões e quatrocentos milhões de dólares). Com uma produção anual superior a 38 milhões t (trinta e oito milhões de toneladas), o Brasil está entre os três maiores produtores mundiais de frutas (IBRAF, 2006). Em 2005, as exportações brasileiras de frutas frescas geraram resultados de cerca de US $\$ 440$ milhões (quatrocentos e quarenta milhões de dólares) para um volume de aproximadamente 828 mil t (oitocentos e vinte e oito mil toneladas). Numa comparação com o ano de 1995, percebe-se um crescimento de $263 \%$, em volume, e de $327 \%$, em valor, em referência ao ano de 2005 (IBRAF, 2006).

Apesar deste crescimento, defende-se que o país ainda esteja distante do seu verdadeiro potencial para exportação de frutas frescas (BRAZILIAN FRUIT, 2006). Tal fato poderia ser atribuído à ausência de habilidade gerencial dos produtores e empresários do setor ou de políticas públicas eficazes que estimulassem a atividade exportadora.

A expressividade do mercado exportador brasileiro de frutas está associada à região do Vale do São Francisco, principal pólo de produção e de exportação de manga e de uva no país (WYZYKOWSKI; ARAÚJO; ALMEIDA, 2002, p.437). A fruticultura irrigada dinamizou a economia e a estrutura urbana locais, dando origem ao aglomerado urbano mais próspero do Vale do São Francisco (CORREIA; ARAÚJO; CAVALCANTE, 2001, p.1-2). De acordo com a Associação dos Produtores e Exportadores de Hortifrutigranjeiros do Vale do São Francisco (VALEXPORT, 2006), em 2005, a região produziu 48.652t (quarenta e oito mil, seiscentos e cinqüenta e duas toneladas) de uva, o que equivale a $95 \%$ das $51.213 \mathrm{t}$ (cinqüenta e um mil, duzentos e treze toneladas) exportadas pelo país. Isso representou um total de US\$107.276.000 (cento e sete milhões, duzentos e setenta e seis mil dólares), dos quais US\$101.912.000 (cento e um milhões, novecentos e doze mil dólares) originados do vale. Quanto à manga, o cenário tem igual importância: no mesmo ano, foram exportadas 104.657 t (cento e quatro mil, seiscentos e cinqüenta e sete toneladas) produzidas na região, $92 \%$ do percentual total do Brasil e US\$66.724.000 contra US\$72.526.000, valor gerado a partir da exportação da fruta.

Dada a contribuição para o desenvolvimento nacional e o caráter emergente da inserção global do Brasil, é pertinente e oportuno investigar esse setor, compreender a dinâmica competitiva das empresas, bem como seus fatores críticos de sucesso. Para investigação, foi selecionado um proeminente competidor, pioneiro em atividades internacionais, o Grupo Fruitfort, fundado em 1982, que vem contribuindo para alavancar os resultados da região como um todo. É o maior exportador de frutas do submédio São Francisco e constitui, portanto, uma fonte relevante de estudos, que permitirá maior aprendizado e inferências significativas sobre práticas empresariais bem-sucedidas no país. Dedicadas ao plantio, ao cultivo, à embalagem e à distribuição global de mangas e uvas, as empresas Fruitfort Agrícola e Exportação, Companhia Agrícola São Francisco e CopaFruit constituem o Grupo Fruitfort. Sua estrutura de packing house (galpão de embalagem das frutas), seus escritórios e suas fazendas estão localizados nessa região, em Petrolina, no estado de Pernambuco. Suas operações de logística e de comercialização estão presentes na América do Sul, nos EUA, no Canadá, na Europa e no Oriente Médio, destacando-se entre os clientes, as maiores cadeias de supermercados e de 
empresas de importação do mundo. Além disso, tem consolidado parcerias, dispondo de escritórios no exterior - nos EUA e na Holanda; instalados em 1992 e 1996, respectivamente -, com vistas a apoiar os clientes no controle de qualidade, na distribuição e na logística. Vale ressaltar ainda que o Fruitfort é o primeiro grupo brasileiro certificado com o Selo Mundial de Procedência do Carrefour, válido para todos os países onde a empresa atua, comprovando sanidade, sabor e qualidade dos frutos e processos produtivos, de acordo com as necessidades sociais e ambientais (FRUITFORT, 2006).

Considerando a relevância da temática, o escopo desta pesquisa dedica-se essencialmente ao estudo do processo de formação de estratégias internacionais, a partir da perspectiva do Grupo Fruitfort, desde a sua fundação até 2006. O debate sobre as fontes de vantagem da fruticultura na competição global orienta-se em torno de três modelos contemporâneos, relevantes para este estudo:

1. Escola Nórdica de Negócios Internacionais de Uppsala (JOHANSON; VAHLNE, 1977; JOHANSON; WIDERSHEIN-PAUL, 1975);

2. Determinantes da vantagem competitiva das nações (modelo Diamante) (PORTER, 1989, 1991, 1999); e

3. Resource-based view (RBV) (BARNEY; 1991, 2002; DHANARAJ; BEAMISH, 2003; FAHY, 1998; PETERAF; 1993; SHARMA; ERRAMILLI, 2004; WERNERFELT, 1984).

O estudo desses modelos dar-se-á de uma perspectiva longitudinal, proposta pela análise das mudanças estratégicas (PETTIGREW, 1985, 1987).

\section{Mudança estratégica}

O caráter longitudinal da pesquisa faz com que conceitos como processos de formação de estratégia - sejam deliberados ou emergentes (MINTZBERG, 1998) -, comportamento e mudança estejam intrinsecamente associados, seja essa pesquisa ligada a reorientações ou a uma seqüência de eventos incrementais a partir de uma ampla estratégia ampla (QUINN, 1978; VAN DE VEN, 1992).

Como metodologia de estudo em processos históricos de mudança, a proposta de Pettigrew (1987) busca explicar características emergentes, holísticas e situacionais de uma organização em seu contexto, em detrimento da divisão do entorno em conjuntos limitados de variáveis dependentes e independentes isoladas. Desse modo, uma análise contextualista envidaria esforços para examinar relações e interdependências entre os mais diversos níveis organizacionais, entre os quais: interesses de grupos internos, liderança e jogos políticos (CHILD, 1972) e variáveis industriais e macroambientais (PORTER, 1986), além da seqüência das ações e eventos, de maneira histórica (CHANDLER, 1992). Essa natureza contextual e processual é a mais adequada para captar nuances na trajetória estratégica das empresas, especialmente, as forças direcionadoras da mudança, a forma como esta se desenvolve e o modo como as organizações descobrem e aproveitam oportunidades (PETTIGREW, 1987).

Mudanças estratégicas, sejam estas incrementais ou quânticas (MINTZBERG, 1998; MINTZBERG; AHLSTRAND; LAMPEL, 2000), devem ser analisadas sob três perspectivas, conforme sugere Pettigrew (1987): 1) conteúdo: o que especificamente mudou (a estratégia adotada pela firma); 2) contextos internos e externos em que ocorreram as mudanças, destacando recursos e competências essenciais, ambientes sociais, político, econômico, tecnológico e cultural, indústria, sinais e movimentos competitivos; e 3) processo ou ainda as ações e reações sistematizadas entre as partes ("como" as mudanças foram operacionalizadas) para deslocar a organização. 


\section{Teorias de internacionalização e sua análise contextualista-processual}

A partir da década de 1960, os estudos sobre a internacionalização das empresas começaram / o estudo sobre a internacionalização das empresas começou a se consolidar com ontologia própria na academia, onde já se registrava a necessidade de comercialização e movimentação de capital entre os países. Isso deu origem a teorias clássicas, como:

1. a do acompanhamento do ciclo de vida do produto (VERNON, 1966, 1969);

2. a do enfoque comportamental e incremental da Escola Nórdica de Negócios Internacionais (JOHANSON; VAHLNE, 1977; JOHANSON; WIDERSHEIN-PAUL, 1975);

3. a dos determinantes da vantagem competitiva das nações (PORTER, 1989, 1991, 1999), já nos anos 1980; e

4. a do paradigma eclético (DUNNING, 1980, 1988).

A partir dos anos 1990, são evidenciadas as contribuições dos conceitos (e decorrentes pesquisas) sobre a escolha adaptativa (LAM; WHITE, 1999) e a resource-based view (RBV). Esta enfatiza / Estas enfatizam os aspectos internos e idiossincráticos da empresa (BARNEY; 1991; GRANT; 1991; PETERAF; 1993; WERNERFELT, 1984) como fundamentais para o sucesso na competição internacional (BARNEY, 2002; DHANARAJ; BEAMISH, 2003; FAHY, 1998; SHARMA; ERRAMILLI, 2004).

Dentre tais modelos foram selecionados, como base para a análise do processo de formação de estratégias internacionais do Grupo Fruitfort, a Teoria de Uppsala, os determinantes da vantagem competitiva nacional e a RBV, pela atenção disponibilizada na literatura acadêmica e por sua aplicabilidade empírica.

A teoria de Uppsala sustenta que a firma é constituída por processos cumulativos de aprendizagem em uma complexa rede de recursos, de competências e de relacionamento (HEMAIS; HILAL, 2002, p.15-20). Por essa razão, esse modelo defende que os estágios do processo de internacionalização da firma não têm base nas estruturas deliberadas e planejadas da análise racional, mas em passos de natureza incremental e de aprendizagem sucessiva, mediante o comprometimento crescente com os mercados estrangeiros (JOHANSON; VAHLNE, 1977, p.26-29; HEMAIS; HILAL, 2002, p.21-22), implicando assim o desenvolvimento orgânico da firma (ANDERSSON; JOHANSON; VAHLNE, 1997).

O modelo Diamante (PORTER, 1989) apregoa a conscientização de um paradigma que trate de características nacionais como estimulantes da vantagem competitiva das indústrias no contexto internacional. Porter (1989) afirma que num sistema de reforço mútuo, quatro determinantes situados no ambiente nacional levariam as empresas a essa situação de vantagem:

1. os fatores de produção;

2. a demanda interna para estimular padrões superiores de competição;

3. os níveis de excelência das indústrias correlatas e de apoio; e

4. a estratégia, a estrutura da empresa e a rivalidade na indústria.

As idéias centrais da RBV, com base nos argumentos de Penrose (1962), residem no entendimento da organização como um portfolio de recursos (WERNERFELT, 1984) e não apenas portfólios de produtos ou de unidades de negócio. Em estratégias de internacionalização e expansão, as organizações deveriam questionar-se sobre quais recursos permitiriam ou ampliariam a vantagem competitiva, bem como definiriam a sequiência de entrada em novos mercados (SHARMA; ERRAMILLI, 2002). À indústria e ao ambiente externo, é dispensado um papel secundário; as oportunidades de crescimento internacional seriam apenas aproveitadas se a organização dispusesse do recurso necessário (WERNERFELT, 1984) ou, ao menos, da proficiência em criálo. Conforme pode ser observado no quadro 1 , em cada um dos modelos teóricos de internacionalização, foram 
identificadas as mais marcantes dimensões da mudança, o que, portanto, atende à recomendação de Pettigrew (1985, 1987) para o estudo do processo, além de posicionar a temática da estratégia internacional sob o "guarda-chuva" maior denominado estratégia empresarial. Vale registrar que essa investigação apresenta um esforço de adequação das principais abordagens teóricas sobre internacionalização "importadas" à realidade das empresas de economias emergentes, visando ao entendimento destas.

\section{Quadro 1}

Dimensões de análise versus modelos de internacionalização

\begin{tabular}{|c|c|c|c|c|c|c|c|c|c|}
\hline \multirow[b]{2}{*}{ Modelo } & \multicolumn{3}{|c|}{ Processo } & \multicolumn{3}{|c|}{ Contexto } & \multicolumn{3}{|c|}{ Conteúdo } \\
\hline & Gradualismo & $\begin{array}{l}\text { Aprendi- } \\
\text { zagem }\end{array}$ & $\begin{array}{c}\text { Distância } \\
\text { psíquica }\end{array}$ & Network & Local & Recurso & $\begin{array}{c}\text { Lideran } \\
\text { ça }\end{array}$ & Oportunismo & $\begin{array}{l}\text { Insight/ } \\
\text { Decisão }\end{array}$ \\
\hline Uppsala & $\mathrm{X}$ & $\mathrm{X}$ & $\mathrm{X}$ & $X$ & & & $\mathrm{X}$ & $\mathrm{X}$ & \\
\hline Diamante & & & & $\mathrm{X}$ & $\mathrm{X}$ & & & & $X$ \\
\hline RBV & $\mathrm{X}$ & & & & & $X$ & $X$ & & $X$ \\
\hline
\end{tabular}

Fonte: elaborado pelos autores.

O conteúdo refere-se aos eventos, às estratégias adotadas e ao modo como estas foram formuladas. Diz respeito ao "que mudou" na organização, parecendo estar intimamente associado à decisão de internacionalizar-se. Se levarmos em conta o foco deste artigo, é, portanto, inerente aos três modelos de internacionalização analisados.

Por sua vez, o contexto refere-se às percepções gerenciais diante das variações ambientais e à forma como estas influenciam as operações da empresa. Responde à questão "por que mudou?".

O processo refere-se ao estudo longitudinal, em que os eventos são estudados numa escala temporal (plano horizontal), elucidando a questão “como mudou?" Essa dimensão é representada de forma bem marcante pela teoria de Uppsala, especialmente, no Brasil, em estágio inicial de internacionalização.

A partir do momento em que as empresas estabelecem suas operações sem saberem ao certo suas reais intenções em relação ao mercado externo (FRANCISCO, 2004), fica evidenciado o caráter emergente e incremental com que as mudanças são operacionalizadas. A aquisição evolutiva do conhecimento experimental por meio do comprometimento crescente (JOHANSON; VAHLNE, 1977) denota que o próprio conteúdo da estratégia, sobrepujado pela dimensão processual nessa perspectiva, tende a ser conservador, tímido e pouco proativo nos estágios iniciais em empresas brasileiras. O oportunismo é presente e dita a tônica da mudança em vários casos brasileiros.

Dadas as três dimensões da metodologia de Pettigrew (1987), (conteúdo, contexto e processo), o modelo proposto pela teoria de Uppsala mais se aproxima da visão processual, enquanto o modelo Diamante é predominantemente contextual externo. A expansão internacional, por meio dos recursos competitivos, enfatiza o contexto interno.

O conteúdo refere-se aos eventos, às estratégias adotadas e ao modo como estas foram formuladas. Diz respeito ao "que mudou" na organização, parecendo estar intimamente associado à decisão de internacionalizar-se. Se levarmos em conta o foco deste artigo, é, portanto, inerente aos três modelos de internacionalização analisados.

Por sua vez, o contexto refere-se às percepções gerenciais diante das variações ambientais e à forma como estas influenciam as operações da empresa. Responde à questão "por que mudou?". 
O processo refere-se ao estudo longitudinal, em que os eventos são estudados numa escala temporal (plano horizontal), elucidando a questão “como mudou?" Essa dimensão é representada de forma bem marcante pela teoria de Uppsala, especialmente, no Brasil, em estágio inicial de internacionalização.

A partir do momento em que as empresas estabelecem suas operações sem saberem ao certo suas reais intenções em relação ao mercado externo (FRANCISCO, 2004), fica evidenciado o caráter emergente e incremental com que as mudanças são operacionalizadas. A aquisição evolutiva do conhecimento experimental por meio do comprometimento crescente (JOHANSON; VAHLNE, 1977) denota que o próprio conteúdo da estratégia, sobrepujado pela dimensão processual nessa perspectiva, tende a ser conservador, tímido e pouco proativo nos estágios iniciais em empresas brasileiras. O oportunismo é presente e dita a tônica da mudança em vários casos brasileiros.

Dadas as três dimensões da metodologia de Pettigrew (1987), (conteúdo, contexto e processo), o modelo proposto pela teoria de Uppsala mais se aproxima da visão processual, enquanto o modelo Diamante é predominantemente contextual externo. A expansão internacional, por meio dos recursos competitivos, enfatiza o contexto interno.

Por sua vez, o quadro 2 apresenta a proposição conjunta na qual fundamenta-se esta pesquisa, numa abordagem contextualista-processual das teorias de internacionalização. Percebem-se indícios de que a Escola de Uppsala e a internacionalização alicerçada na RBV estão intimamente relacionadas, uma vez que a empresa e o contexto predominantemente interno constituem a unidade de análise considerada. Cabe ressaltar que a categorização das características das escolas, associadas às variáveis da mudança, dá-se em caráter linear, teórico e explicativo. É possível perceber sintomas de imbricamento entre as dimensões, o que não inviabiliza, contudo, a aplicação dos conceitos para as análises empíricas. Por essa razão, de acordo com a proposta de Pettigrew (1987) e com os objetivos desta investigação, o framework utilizado como base para a análise do processo de formação de estratégias internacionais do Grupo Fruitfort é apresentado na figura 1. A utilização desse framework dar-se-á mediante a identificação dos eventos e/ou episódios que compuseram as estratégias internacionais do grupo e análise desses eventos mediante a relação concomitante entre os três modelos de internacionalização destacados. 
Quadro 2 Análise contextualista-processual dos modelos de internacionalização

\begin{tabular}{|c|c|c|c|}
\hline \multirow{2}{*}{$\begin{array}{c}\text { MUDANÇA } \\
\text { ESTRATÉGICA }\end{array}$} & \multicolumn{3}{|c|}{ MODELOS DE INTERNACIONALIZAÇÃO } \\
\hline & Uppsala & Diamante & RBV \\
\hline Conteúdo & $\begin{array}{l}\text { - Unidade de análise: } \\
\text { empresa } \\
\text { - Teoria do conhecimento e } \\
\text { aspecto idiossincrático à firma } \\
\text { - Comprometimento das } \\
\text { decisões } \\
\text { - Oportunismo } \\
\text { - Conseqüência majoritária } \\
\text { do processo }\end{array}$ & $\begin{array}{l}\text { - Unidade de análise: } \\
\text { indústria } \\
\text { - Subvértice: estratégia da } \\
\text { empresa } \\
\text { - Criação de pressões para } \\
\text { inovação } \\
\text { - Procurar, como } \\
\text { motivação, concorrentes mais } \\
\text { capazes } \\
\text { - Localização da base } \\
\text { doméstica para o sucesso } \\
\text { internacional }\end{array}$ & $\begin{array}{l}\text { - Unidade de análise: } \\
\text { empresa } \\
\text { - } \quad \text { Adequação da } \\
\text { organização quanto a recursos, } \\
\text { capacidades e competências, } \\
\text { para competir no mercado } \\
\text { internacional } \\
\text { - Heterogeneidade e } \\
\text { imobilidade imperfeita dos } \\
\text { recursos }\end{array}$ \\
\hline Contexto & $\begin{array}{l}\text { - Contexto essencialmente } \\
\text { interno } \\
\text { - Escolha de mercados pela } \\
\text { distância psíquica } \\
\text { - Existência de parceiros de } \\
\text { excelência internacional, } \\
\text { especialmente, nos estágios } \\
\text { iniciais da internacionalização } \\
\text { - Nível de risco do contexto } \\
\text { externo reduzido pelo } \\
\text { andamento do processo } \\
\text { - Informações incompletas } \\
\text { do ambiente externo }\end{array}$ & $\begin{array}{l}\text { - } \quad \text { Contexto essencialmente } \\
\text { extern } \\
\text { - } \quad \text { Atributos nacionais como } \\
\text { determinantes da vantagem } \\
\text { competitiva na indústria } \\
\text { - Subvértice: rivalidade } \\
\text { interna na indústria } \\
\text { - Vértice: condições dos } \\
\text { fatores de produção } \\
\text { - Vértice: condições da } \\
\text { demanda interna } \\
\text { - Aspectos político- } \\
\text { governamentais } \\
\text { - Caráter predominante } \\
\text { sobre as demais esferas de } \\
\text { análise }\end{array}$ & $\begin{array}{l}\text { - Contexto essencialmente } \\
\text { interno } \\
\text { - Contexto interno: } \\
\text { recursos como fonte de } \\
\text { vantagem competitiva } \\
\text { sustentável } \\
\text { - Contexto externo: } \\
\text { minoradas análises } \\
\text { macroambientais e industriais }\end{array}$ \\
\hline Processo & $\begin{array}{l}\text { - Aprendizagem } \\
\text { incremental: como mudar e os } \\
\text { estágios da inserção } \\
\text { internacional } \\
\text { - Acúmulo de experiência e } \\
\text { a importância do conhecimento } \\
\text { experiencial } \\
\text { - Natureza emergente e } \\
\text { oportunista } \\
\text { - Relacionamento com } \\
\text { parceiros externos (network) } \\
\text { - Atividades correntes e o } \\
\text { mecanismo básico de } \\
\text { internacionalização } \\
\text { - Caráter predominante } \\
\text { sobre as demais dimensões de } \\
\text { análise }\end{array}$ & $\begin{array}{l}\text { - Subvértice: Estrutura da } \\
\text { empresa, modo de condução } \\
\text { das atividades, políticas e } \\
\text { metas para viabilizar a } \\
\text { oportunidade oferecida pelo } \\
\text { país } \\
\text { - } \quad \text { Sistema dinâmico de } \\
\text { reforço mútuo } \\
\text { - Criação de fatores } \\
\text { avançados para alavancar a } \\
\text { vantagem competitiva } \\
\text { - Articulação das } \\
\text { atividades na cadeia de valor } \\
\text { pela demanda contingencial do } \\
\text { ambiente nacional }\end{array}$ & $\begin{array}{l}\text { - Seqüência de entrada } \\
\text { delineada pela disposição dos } \\
\text { recursos e habilidades de } \\
\text { transferência } \\
\text { - Presente de forma mais } \\
\text { marcante em estágios } \\
\text { avançados de } \\
\text { internacionalização } \\
\text { - Consequiência das } \\
\text { dimensões anteriores }\end{array}$ \\
\hline
\end{tabular}




\section{Figura 1}

Análise retrospectiva dos eventos (Ev) que compõem as estratégias de internacionalização das empresas, com base no framework conceitual integrativo (modelos teóricos)

- Gradualismo/processo

incremental;

- Aprendizado e conhecimento

experiencial;

- Networks.

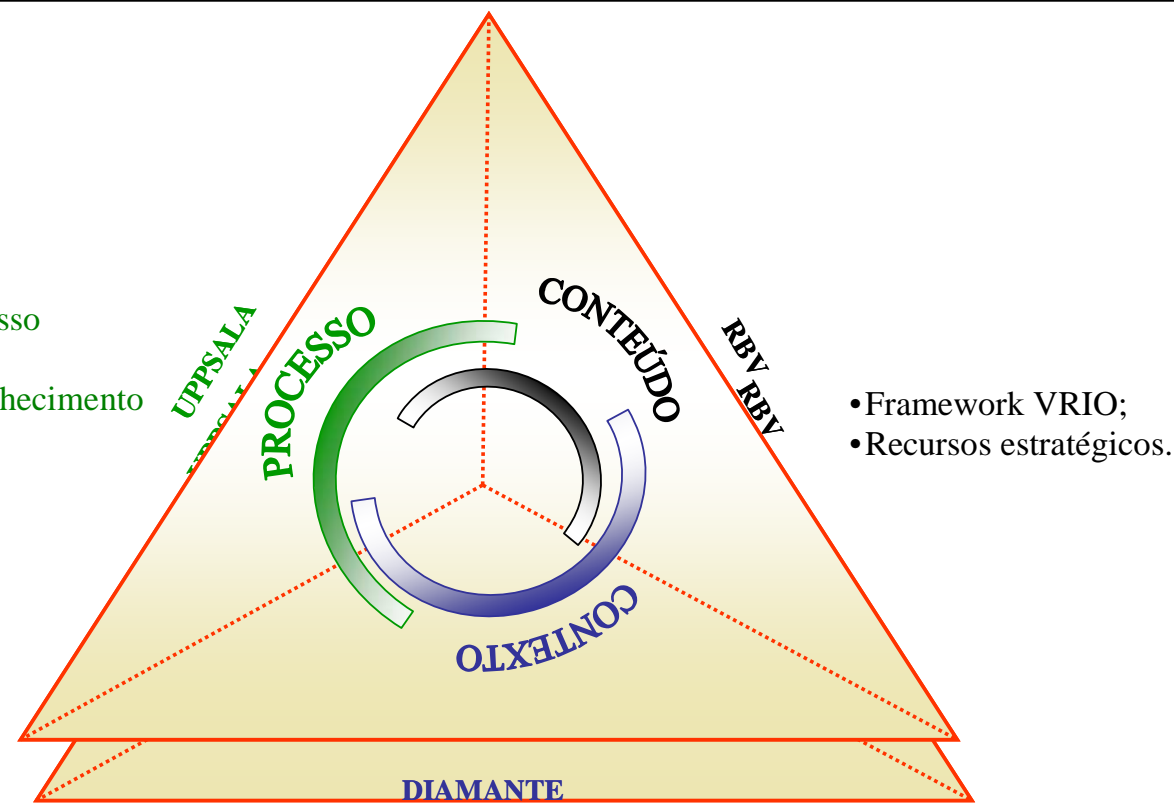

DIAMANTE

- Condições dos fatores; condições da demanda; indústrias correlatas e de apoio; estratégia, estrutura e rivalidade.

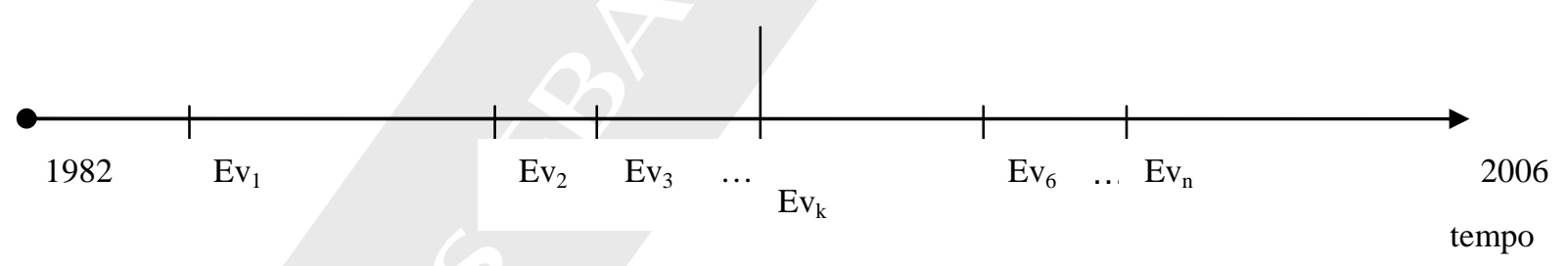

Fonte: elaborada pelos pesquisadores.

Quanto ao modelo Diamante, percebe-se um predomínio do contexto, especificamente externo, quando comparado às demais dimensões da mudança, posto que os atributos nacionais seriam responsáveis pela vantagem competitiva, pela produtividade e pelo crescimento da indústria.

O quarto determinante da vantagem competitiva das nações engloba as três dimensões da mudança, quando da estratégia da empresa (conteúdo), estrutura organizacional (processos internos) e rivalidade da indústria (contexto), denotando circunstâncias nacionais, influência ambiental nas práticas, metas e políticas gerenciais. O conteúdo das estratégias presente na RBV estudo dedica atenção para o adequado emprego dos recursos e, por conseguinte, a vantagem competitiva sustentável. O processo da mudança (ou a seqüência de ações ao 
longo do tempo) seria pautado pela capacidade da organização transferir habilidades e competências entre as fronteiras.

\section{Aspectos metodológicos}

Esta pesquisa tem como objetivo central analisar as características do processo de formação de estratégias internacionais do Grupo Fruitfort, no período de 1982 a 2006, à luz das teorias de Uppsala, do modelo Diamante e da resource-based view, associadas à mudança estratégica. Trata-se de um estudo de caso qualitativo, do tipo exploratório (MALHOTRA, 2004; MERRIAM, 1998), de cunho analítico e retrospectivo, ex-post facto, em que foram investigadas variáveis que se formam espontaneamente em determinado contexto histórico (MATOS; VIEIRA, 2001, p.44).

O estudo de caso não é apenas um método, mas a escolha de um objeto a ser estudado (STAKE, 1995), examinando o fenômeno dentro de seu contexto (YIN, 2001). Corroborando a argumentação de Pettigrew (1985), o ponto forte dos estudos de caso reside na capacidade de explorar processos sociais à medida que eles se desenrolam nas organizações, permitindo uma análise processual, contextual e longitudinal das várias ações, eventos e significados que se manifestam e são construídos nas organizações (HARTLEY, 1994 apud ROESCH, 1999, p.197-198).

Entre os critérios para seleção da empresa, argumenta-se que a companhia foi pioneira em ações proativas para internacionalização na região do submédio do São Francisco, influenciando de forma direta o reconhecimento e o desenvolvimento local. Ademais, apresenta padrões de estratégias bem-sucedidos, papel significativo da liderança pessoal em momentos de mudança, além da facilidade de acesso para os pesquisadores. Nesta pesquisa, a seleção da amostra foi tida como não-probabilística intencional por conveniência (PATTON, 2001; MERRIAM, 1998). A amostra foi composta por quatro respondentes de instituições correlatas à fruticultura do semi-árido (gestores da Codevasf, do Sebrae, da Embrapa e da Valexport) e 11 executivos responsáveis pela administração estratégica da empresa caso, que detivessem conhecimento acerca da sua trajetória. O principal método de coleta de dados foi a realização de entrevistas semi-estruturadas, complementadas com a pesquisa documental e a observação não-participante, na perspectiva da triangulação dos dados. As entrevistas ocorreram em maio, junho, outubro e dezembro de 2006.

Foi utilizada na análise deste estudo a construção de categorias por meio da codificação e do método de comparação constante (MERRIAM, 1998). Como sugere Gomes (2004, p.70), as categorias finais resultaram da comparação entre as categorias gerais, estabelecidas antes do campo, com as específicas, formuladas após a coleta.

\section{Análise dos resultados}

Em harmonia com a recomendação de Pettigrew (1987) sobre a importância da compreensão dinâmica dos processos de estratégia, na medida em que eles se desenvolvem, - e, especificamente, com a de Welch e Luostarinen (1988, p. 34-35) e a de Melin (1992) quanto à internacionalização das empresas -, a trajetória do Grupo Fruitfort foi subdividida em quatro fases. Isso foi feito de acordo com os eventos e/ou episódios mais marcantes vividos, conforme evidenciado ao longo das entrevistas com os executivos da empresa. É possível afirmar que o padrão de formação de estratégias internacionais do Grupo Fruitfort, ao longo do período delineado, manteve-se constante e gradual, seguindo a decisão inicial pela internacionalização (conteúdo). A empresa perseguiu continuamente esse objetivo, muito embora tenha vivenciado diversas dificuldades, desde aquelas associadas às questões climáticas, políticas ou macroeconômicas, até as necessidades de reestruturação orgânica e de maior profissionalização de suas atividades. 
Em 1982, ano de fundação da empresa, percebeu-se uma forte influência tanto da implantação dos projetos de irrigação pela Codevasf (Companhia de Desenvolvimento dos Vales do São Francisco e do Parnaíba) quanto dos agentes externos, na decisão dos empresários de iniciar a internacionalização. Com o contexto bastante favorável, as estratégias do grupo foram, de maneira geral, deliberadas, orientadas pela intenção de ganho de competência no mercado internacional com o comércio de perecíveis. A exportação de melão deu à empresa o caráter de player expressivo nessa indústria, tanto que em 1984 já era a maior exportadora da fruta no Nordeste. Em 1985, teve início a venda de mangas ao mercado europeu.

A fase dois foi marcada pela continuidade das ações praticadas, pelo estabelecimento de parcerias e pelo investimento na produtividade. Poucos foram os eventos marcantes, como se a fase fosse unicamente uma preparação da empresa para os anos seguintes, de intensa concorrência e crescimento da participação nacional no comércio mundial de frutas. Nessa fase, a região do submédio já começava a despontar nacionalmente como importante centro de exportação, atraindo a atenção não apenas dos competidores, mas de instituições de apoio como bancos, agências governamentais e indústrias correlatas. $\mathrm{O}$ foco à época era apenas o mercado europeu. O pioneirismo do Grupo Fruitfort fez com que sua atenção se voltasse para o então inédito mercado norteamericano, para a identificação de um gap de três meses em sua janela de importação de manga e pela abertura do primeiro escritório de uma empresa do submédio no exterior.

$\mathrm{Na}$ terceira fase deu-se o início efetivo das exportações para os EUA. Isso exigiu do grupo um forte investimento em tecnologia, para adequar o processo produtivo às exigências fitossanitárias do novo mercado, reforçando os pilares da empresa em qualidade e em produtividade. A concorrência foi intensificada, o que culminou na paulatina corrosão da vantagem competitiva do grupo, alcançada por seu pioneirismo e visão de mercado. Era preciso desenvolver novas competências empresariais, reforçar o poder de recursos idiossincráticos e preparar seu modelo de gestão para atuar de novas formas, mais agressivas comercialmente, mais dinâmicas e profissionalizadas. Aliado a isso, o contexto externo macroeconômico apresentava-se desfavorável, dadas as dificuldades de concessão de crédito à agricultura de exportação, advindas com a implantação do Plano Real em 1994. O cenário descrito culminou no primeiro episódio de reestruturação orgânica vivido pelo grupo, no período de 1994 a 1996. Essa estratégia, segundo os entrevistados, foi traumática, mas decisiva para que o grupo retomasse o caminho certo para o crescimento sobre bases mais sólidas de gestão. Essa fase foi marcada ainda pela abertura de um escritório em Roterdã, na Holanda - para minimizar a interferência dos intermediários nas exportações da empresa, dotando-a de maior controle sobre a atividade comercial - e pela substituição, nos EUA, em 1999, do escritório de Miami por outro localizado na cidade de Filadélfia.

No ano de 2000, a empresa deu início às exportações de uvas sem semente, sob forte influência dos parceiros correlatos que, desde o início da década de 1990, engendravam esforços de pesquisa da fruta. O profissionalismo empresarial ditou as regras às empresas no submédio e o clima demonstrou o quanto a atividade é susceptível às suas intempéries: as fortes chuvas, associadas à ausência de apoio governamental, fizeram com que vários produtores fechassem as portas. Os prejuízos para o Grupo Fruitfort foram seriamente sentidos. Após uma tentativa frustrada de fusão com três outras empresas de fruticultura no Nordeste, a empresa vivenciou seu segundo episódio de reestruturação orgânica. Suas estratégias compreenderam ainda o investimento em novas variedades de manga - a fim de aproveitar oportunidades nos mercados norteamericano e europeu -, e o começo das exportações para o Japão, iniciativa favorecida pela instalação da biofábrica de moscas estéreis na região, em 1993.

Foram categorizados e sintetizados no quadro 3, os eventos e as fases da trajetória do grupo, de acordo com a dimensão de conteúdo e seus respectivos processo e contexto. As dimensões mais relevantes para cada fase estão em destaque no estilo sombreado. Contudo, vale ressaltar que, corroborando o argumento de Petrigrew (1987), as três dimensões, simultaneamente, fizeram parte de toda a trajetória da empresa. Tais destaques foram atribuídos àquelas que originaram a mudança ou se sobrepuseram às demais, em cada fase específica. 
Quadro 3

Dimensões da mudança nas fases da trajetória do Grupo Fruitfort

\begin{tabular}{|c|c|c|c|}
\hline \multirow{2}{*}{ FASES } & \multicolumn{3}{|c|}{ DIMENSÕES } \\
\hline & Conteúdo & Contexto & Processo \\
\hline $\begin{array}{c}\text { Fase 1 } \\
(1982-1985)\end{array}$ & $\begin{array}{l}\text { - Fundação da empresa } \\
\text { - Exportação de manga para } \\
\text { a UE }\end{array}$ & $\begin{array}{l}\text { - Projetos de irrigação; fatores de } \\
\text { produção } \\
\text { - Janelas de exportação }\end{array}$ & $\begin{array}{l}\text { - } \text { Aquisição de lotes } \\
\text { VSF } \\
\text { - } \\
\text { Aprendizagem }\end{array}$ \\
\hline $\begin{array}{c}\text { Fase } 2 \\
(1986-1992)\end{array}$ & $\begin{array}{l}\text { - Plantio alta densidade } \\
\text { - Escritório em Miami }\end{array}$ & $\begin{array}{l}\text { Chegada de novos players; } \\
\text { fatores de produção }\end{array}$ & $\begin{array}{ll}\text { - } & \text { Crescimento gradual } \\
\text { - } & \text { Produtividade } \\
\text { - } & \text { Aprendizagem } \\
\text { - } & \text { Parcerias } \\
\end{array}$ \\
\hline $\begin{array}{c}\text { Fase 3 } \\
(1993-1999)\end{array}$ & $\begin{array}{l}\text { - Exportação de manga para } \\
\text { os EUA } \\
\text { - Novo modelo de gestão } \\
\text { - Implantação área uva } \\
\text { - Escritório em Roterdã }\end{array}$ & $\begin{array}{l}\text { - Janelas de exportação } \\
\text { - Projeto da uva sem semente } \\
\text { - Concorrência intensificada } \\
\text { - Plano Real } \\
\text { - Aeroporto em Petrolina }\end{array}$ & $\begin{array}{l}\text { - } \\
\text { Parcerias } \\
\text { - } \quad \text { Profissionalismo } \\
\text { - } \\
\text { Episódio de } \\
\text { reestruturação }\end{array}$ \\
\hline $\begin{array}{c}\text { Fase } 4 \\
(2000-2006)\end{array}$ & $\begin{array}{l}\text { - Exportação uva para } \\
\text { UE/EUA } \\
\text { - Aquisição da CopaFruit } \\
\text { - Novo modelo de gestão } \\
\text { - Novas variedades de } \\
\text { manga } \\
\text { - Exportação para o Japão }\end{array}$ & $\begin{array}{l}\text { - Instalação de biofábrica na } \\
\text { região } \\
\text { - Fortes chuvas; fatores de } \\
\text { produção } \\
\text { - Demanda por novas variedades } \\
\text { - Aval dos clientes japoneses } \\
\text { (fitossanidade) }\end{array}$ & $\begin{array}{ll}\text { - } & \text { Produtividade } \\
\text { - } & \text { Episódio de } \\
& \text { reestruturação }\end{array}$ \\
\hline
\end{tabular}

Fonte: pesquisa de campo.

A partir do exposto, foram realizadas as análises dos dados coletados nesta investigação, sobre a visão dos modelos de internacionalização supracitados. Para a teoria de Uppsala, foram analisados pilares como a aprendizagem, o gradualismo, a distância psíquica e as networks. Os determinantes do modelo Diamante são a influência do governo e da cultura; enquanto liderança empreendedora e demais recursos competitivos dizem respeito à RBV.

A convergência dos conceitos apregoados pela Escola Nórdica ocorreu mais acentuadamente na segunda fase do processo, com a continuidade das ações e o gradualismo evidenciados; na última, com o reforço das networks na consolidação da empresa. O modo como a empresa expandiu suas operações foi particularmente marcado pelo incrementalismo e pelo comprometimento gradual das decisões e dos recursos alocados. Ademais, a aprendizagem internacional muito contribuiu para as decisões de investimento do grupo. Com as devidas adaptações à realidade do submédio e à competência da empresa, contribuiu para incrementar a atividade produtiva da mesma e possibilitou-lhe conhecer melhor a concorrência e os clientes, tornando suas estratégias mais eficazes. Apenas a distância psíquica, como pilar da teoria para escolha dos mercados, não foi percebida na trajetória da empresa. Tal escolha deu-se mediante o aproveitamento das janelas comerciais dos grandes pólos importadores de fruta já existentes no mercado. Os gestores perceberam que no período entre o final de agosto e outubro, não havia fornecimento da manga e da uva frutas por parte dos outros players, a exemplo do Equador, Peru, Chile, Índia e México, por limitações climáticas. Assim, o mercado da Fruitfort é global, nessa época específica do ano. Acrescenta-se ainda o fato do início das operações para o Japão, país culturalmente mais distante do Brasil, segundo Fernandes e Rocha (2005). 
Por outro lado, o modelo parece não ter sido concebido para explicar empresas do tipo born global, como o Grupo Fruitfort. O mecanismo básico de internacionalização, idealizado por Johanson e Valhne (1977) prevê que os "estados" representados pelo conhecimento e pelo comprometimento com o mercado são alavancados pelas "mudanças". Estas, de modo gradual, implicam um comprometimento das decisões e uma adequação das atividades correntes com as necessidades da demanda externa. Ocorre que no grupo, desde sua fundação, as decisões e atividades já são plenamente comprometidas com o ambiente internacional; o que, a princípio, poderia indicar que o referido mecanismo não percebeu aplicabilidade no fenômeno estudado.

É possível afirmar que a pauta de exportações dos estados nordestinos brasileiros ainda é composta por setores de processamento básico, por commodities e por produtos da indústria tradicional (XAVIER; VIANA, 2005, p.457). Isso corrobora o argumento de Porter (1989) sobre a importância da especialização, da inovação e da produtividade nacional para o sucesso global, muito embora seu estudo tenha tratado de indústrias sofisticadas em países desenvolvidos. Essa foi a realidade encontrada na região do submédio: a economia do pólo gira em torno da atividade empresarial de exportação de manga e uva e este é considerado o maior centro especializado do país para esse fim.

O modelo Diamante teve, em seus determinantes, convergência com as estratégias internacionais adotadas pelo Grupo Fruitfort em todas as fases de sua trajetória, de modo que as vantagens de localização estiveram continuamente presentes. Acerca das condições dos fatores, os entrevistados apontam que o clima semi-árido (que minimiza a proliferação das pragas nas plantações, dada a baixa umidade) e a água do rio São Francisco, associados aos projetos de irrigação promovidos pela Codevasf, viabilizam a competição internacional de alto nível da indústria. Destaca-se também a presença de indústrias correlatas e de apoio de excelência, a exemplo da fábrica de moscas estéreis como exigência fitossanitária dos mercados externos (o que foi crucial para o início das operações no Japão) e instituições como a Embrapa, o Sebrae, a Valexport, o Senac e o Senai. É comum aos sujeitos da pesquisa o argumento de que a região concentra um número significativo de parceiros que impulsionam as empresas competidoras de maneira ímpar. Constata-se ainda a presença de rivais locais fortes, como os grupos Queiroz Galvão e Carrefour, investindo em tecnologia e elevando o padrão da fruticultura como um todo.

À exceção do vértice condições da demanda (uma vez que o foco é prioritariamente externo, com padrões de consumo e qualidade de produção bem diferenciados dos consumidores domésticos), os demais foram validados no fenômeno investigado. No entanto, como citado, as associações entre os modelos de internacionalização foram evidentes, muitas vezes, com os pesquisadores encontrando dificuldades na categorização isolada das dimensões, porventura, atribuídas de forma mais expressiva a uma teoria. Tais dimensões reforçam-se mutuamente. Por exemplo, o domínio do clima, como fator de produção dos mais expressivos para o sucesso da região, foi alcançado mediante o conhecimento experiencial no ambiente internacional e o corpo técnico que forma o grupo. O desenvolvimento de tecnologia é interno: isso faz com que a sofisticação dos fatores de produção ocorra por meio da intervenção direta das empresas, o que só é possível com o aprimoramento das competências essenciais e com decisões de investimento adequadas.

A RBV teve como seu representante de maior expressão, no processo de formação de estratégias internacionais do grupo, a liderança empreendedora e a cultura organizacional. Os líderes, em especial, fizeram a diferença e foram classificados como competências essenciais entre os entrevistados. À medida que as variações no ambiente externo e as oportunidades tornaram-se disponíveis para todas as empresas, a visão dos executivos e o modo dinâmico com que eles conduziam suas atividades permitiram à empresa perfazer uma trajetória bemsucedida, colocando-se em posição de vantagem competitiva na região. Ressalta-se ainda a cultura corporativa voltada para a inovação e suporte às estratégias adotadas, bem como o nível do know-how do corpo técnico e o desenvolvimento de tecnologias internamente.

Da perspectiva da RBV, o processo seria pautado pela capacidade da organização transferir habilidades e competências entre as fronteiras, donde as oportunidades de crescimento internacional seriam apenas 
aproveitadas se a empresa dispusesse do recurso necessário ou, ao menos, da proficiência em criá-lo. Se for válido que o contexto externo apresentou as condições iniciais favoráveis e subsidiou com seus recursos e fatores de produção toda a trajetória da empresa e que o processo foi importante para que a empresa desenvolvesse suas competências de produção e mercado, adequando-se eficazmente às necessidades dos clientes, registra-se que houve um contínuo orquestramento dessas variáveis por parte da liderança, atributo do ambiente interno e recursos competitivo promovido pela RBV. O que ocorre é a concomitância entre as perspectivas teóricas, apresentando-se na prática: o ambiente industrial, cujo símbolo é o modelo Diamante, alavancando as empresas como um todo, e os preceitos da RBV explicando as diferenças específicas entre elas.

No quadro 4 encontram-se sintetizadas as estratégias competitivas do Grupo Fruitfort, no período de 1982 e 2006, os modelos de internacionalização com maior presença, bem como a natureza da estratégia, se deliberada ou emergente. Conforme revistas na literatura, algumas dimensões percebem destaque em cada um dos modelos de internacionalização adotados como base, donde é possível relacioná-las com as fases e eventos críticos na trajetória de internacionalização da empresa, da mesma forma que com o tipo de estratégia, se majoritariamente deliberada ou emergente. Desse modo, é possível perceber que a aproximação dos modelos com as estratégias da empresa foi dinâmica, não sendo constantes ao longo do tempo. 


\section{Quadro 4}

\section{Processo de formação de estratégias internacionais do Grupo Fruitfort}

\begin{tabular}{|c|c|c|c|c|}
\hline $\begin{array}{l}\text { Fases na } \\
\text { trajetória } \\
\text { internacional } \\
\text { do grupo }\end{array}$ & Estratégias realizadas & Modelos & $\begin{array}{l}\text { Dimensões } \\
\text { adotadas }\end{array}$ & Tipos de estratégia \\
\hline \multirow{4}{*}{$\begin{array}{l}\text { Fase } 1 \\
(1982-1985)\end{array}$} & $\begin{array}{l}\text { - Crescimento: aquisição dos lotes em São Francisco e } \\
\text { Curaçá }\end{array}$ & Diamante & $\begin{array}{l}\text { Localização } \\
\text { Liderança }\end{array}$ & Deliberada \\
\hline & $\begin{array}{l}\text { - Desenvolvimento do produto: investimento no } \\
\text { plantio de manga }\end{array}$ & Diamante & Localização & Deliberada \\
\hline & $\begin{array}{l}\text { - Desenvolvimento de competências: exportação de } \\
\text { melão }\end{array}$ & Uppsala & Aprendizagem & Emergente \\
\hline & $\begin{array}{l}\text { - Expansão internacional: início da exportação para a } \\
\text { UE. }\end{array}$ & $\begin{array}{l}\text { Diamante } \\
\text { RBV }\end{array}$ & $\begin{array}{l}\text { Localização } \\
\text { Liderança }\end{array}$ & Deliberada \\
\hline \multirow{3}{*}{$\begin{array}{l}\text { Fase } 2 \\
(1986-1992)\end{array}$} & $\begin{array}{l}\text { - Desenvolvimento de competências: conhecimento do } \\
\text { mercado }\end{array}$ & Uppsala & $\begin{array}{l}\text { Oportunismo } \\
\text { Networks } \\
\text { Aprendizagem }\end{array}$ & Emergente \\
\hline & - Crescimento: investimento na produtividade & $\begin{array}{l}\text { Diamante } \\
\text { Uppsala }\end{array}$ & $\begin{array}{l}\text { Localização } \\
\text { Gradualismo }\end{array}$ & Deliberada \\
\hline & - Alianças: estabelecimento de parcerias internacionais & Uppsala & $\begin{array}{l}\text { Networks } \\
\text { Aprendizagem }\end{array}$ & Emergente \\
\hline \multirow{5}{*}{$\begin{array}{l}\text { Fase } 3 \\
(1993-1999)\end{array}$} & $\begin{array}{l}\text { - Expansão internacional: início das operações nos } \\
\text { EUA }\end{array}$ & Diamante & $\begin{array}{l}\text { Localização } \\
\text { Liderança }\end{array}$ & Deliberada \\
\hline & $\begin{array}{l}\text { - Diversificação de atividades: abertura subsidiária } \\
\text { nos EUA }\end{array}$ & $\begin{array}{l}\text { Uppsala } \\
\text { RBV }\end{array}$ & $\begin{array}{l}\text { Liderança } \\
\text { Gradualismo }\end{array}$ & Deliberada \\
\hline & - Alinhamento ambiental: reestruturação orgânica & $\begin{array}{l}\text { Diamante } \\
\text { RBV }\end{array}$ & $\begin{array}{l}\text { Localização } \\
\text { Cultura } \\
\text { Liderança }\end{array}$ & $\begin{array}{l}\text { Deliberadamente } \\
\text { emergente }\end{array}$ \\
\hline & $\begin{array}{l}\text { - Diversificação da produção: investimento na uva sem } \\
\text { semente }\end{array}$ & Diamante & Localização & Deliberada \\
\hline & $\begin{array}{l}\text { Diversificação de atividades abertura subsidiária na } \\
\text { Holanda }\end{array}$ & $\begin{array}{l}\text { Uppsala } \\
\text { RBV }\end{array}$ & $\begin{array}{l}\text { Gradualismo } \\
\text { Liderança }\end{array}$ & Deliberada \\
\hline \multirow{6}{*}{$\begin{array}{l}\text { Fase } 4 \\
(2000-2006)\end{array}$} & - Crescimento: aquisição da CopaFruit & Diamante & $\begin{array}{l}\text { Localização } \\
\text { Liderança }\end{array}$ & Deliberada \\
\hline & $\begin{array}{l}\text { - Expansão internacional: exportação de uva sem } \\
\text { semente }\end{array}$ & Diamante & Localização & Deliberada \\
\hline & - Reposicionamento: tentativa de fusão & $\begin{array}{l}\text { Uppsala } \\
\text { Diamante } \\
\text { RBV }\end{array}$ & $\begin{array}{l}\text { Liderança } \\
\text { Localização } \\
\text { Aprendizagem }\end{array}$ & Deliberada \\
\hline & - Alinhamento ambiental: reestruturação orgânica & RBV & $\begin{array}{l}\text { Cultura } \\
\text { Liderança }\end{array}$ & $\begin{array}{l}\text { Deliberadamente } \\
\text { emergente }\end{array}$ \\
\hline & - Reposicionamento: investimento kent/hallen & $\begin{array}{l}\text { Diamante } \\
\text { RBV }\end{array}$ & $\begin{array}{l}\text { Localização } \\
\text { Liderança }\end{array}$ & Deliberada \\
\hline & $\begin{array}{l}\text { - Expansão internacional: início das operações com o } \\
\text { Japão }\end{array}$ & Diamante & $\begin{array}{l}\text { Localização } \\
\text { Liderança }\end{array}$ & Deliberada \\
\hline
\end{tabular}

Fonte: pesquisa de campo.

Diante dos argumentos discutidos ao longo deste artigo, faz-se um resgate do framework apresentado na figura 1, com as devidas adaptações, dada a realidade vivenciada pela empresa em seu processo de formação de estratégias internacionais (figura 2). Na linha do tempo constam os eventos que, na opinião dos entrevistados, foram os mais expressivos na trajetória da empresa, a partir daqueles apresentados nos quadros 3 e 4. 
Figura 2- Framework conceitual integrativo e o processo de formação de estratégias internacionais do Grupo Fruitfort: modelos e mudanças

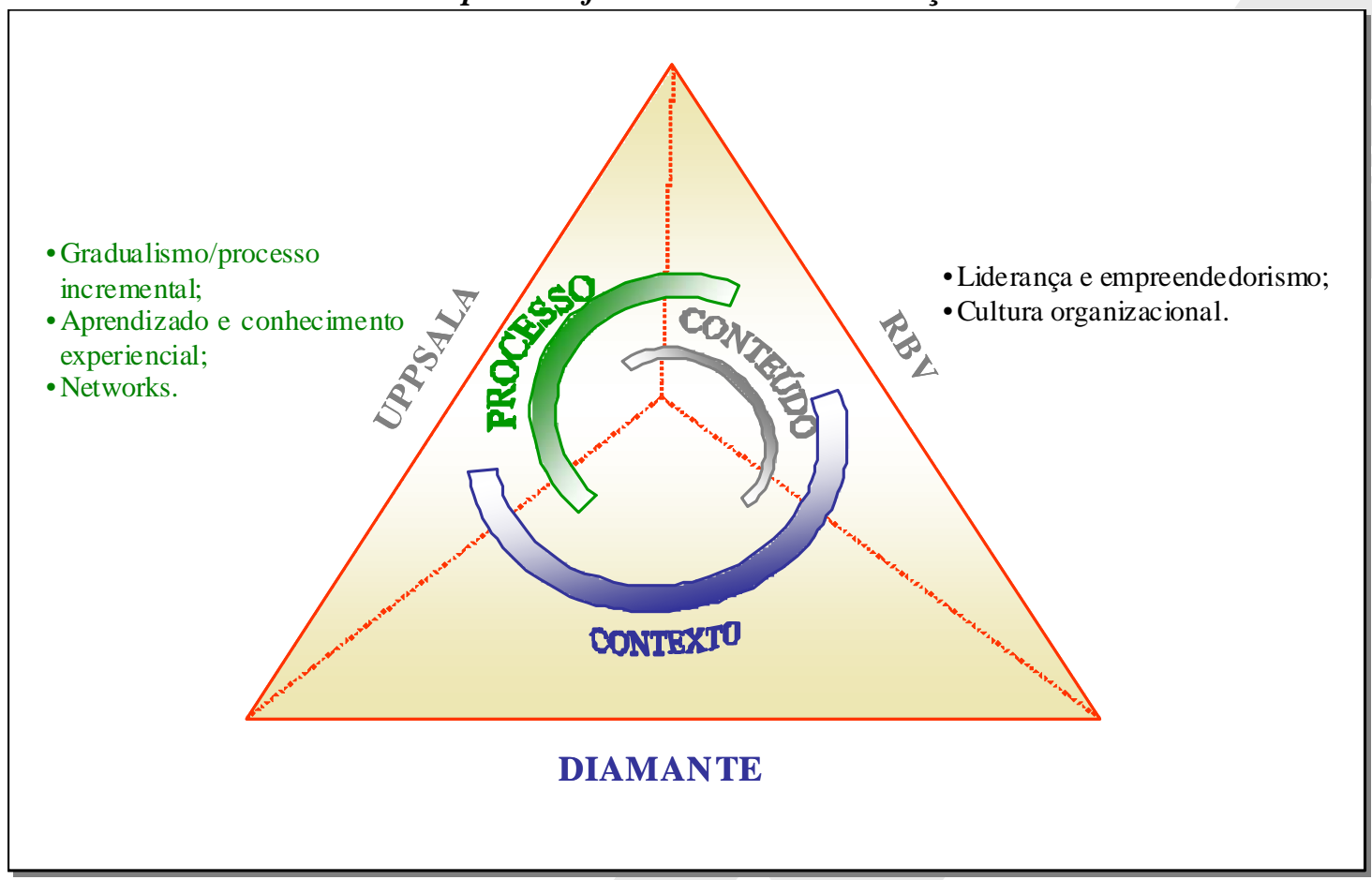

- Condições dos fatores; *Aspectos político-legais; *Indústrias correlatas e de apoio; *Estratégia, Estrutura e Rivalidade.

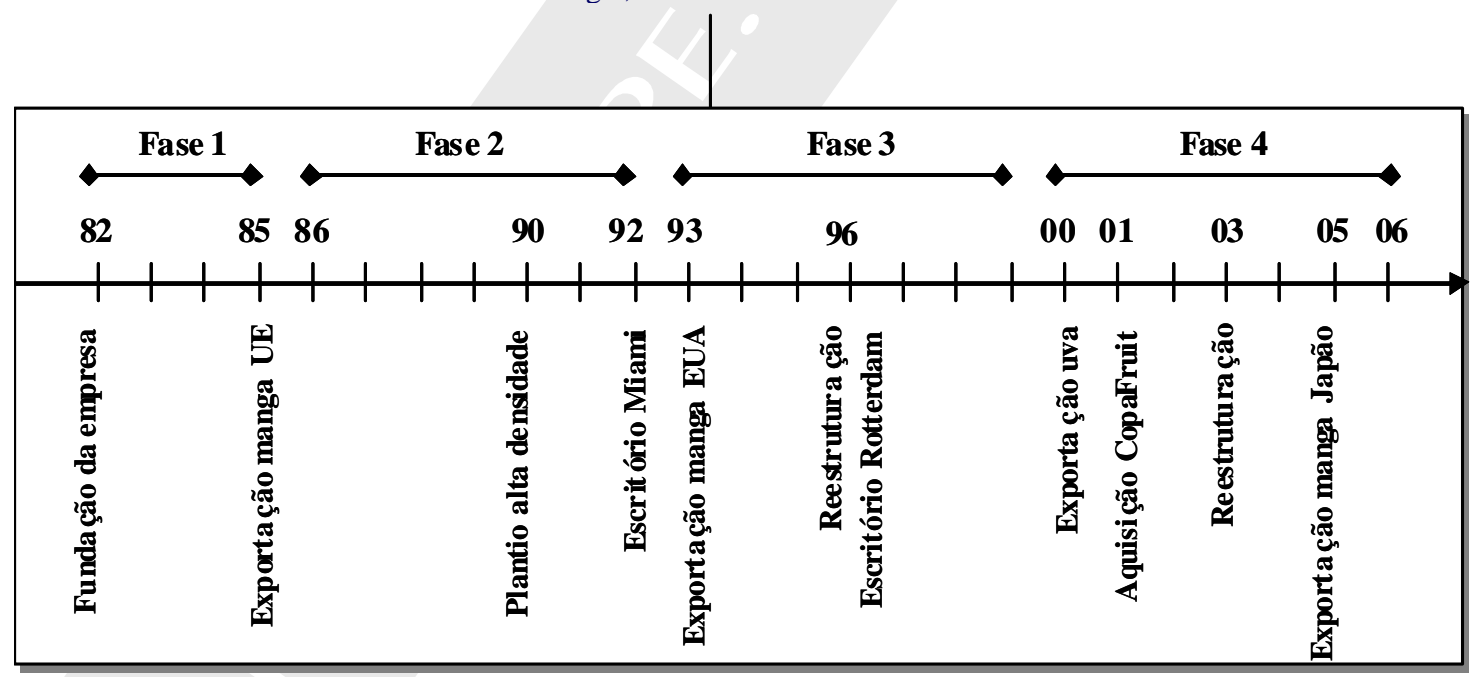




\section{Conclusões}

O Grupo Fruitfort vivenciou quatro grandes fases, conforme os dados coletados com os respondentes e provenientes da pesquisa documental. Nessas fases, foram observadas as estratégias internacionais realizadas, quer fossem pretendidas ou não, os eventos e episódios mais marcantes e as mudanças originadas nos ambientes interno e externo à empresa. Tem-se que o processo de formação das estratégias internacionais do Grupo Fruitfort, ao longo do período delineado nesta investigação, ocorreu de uma perspectiva deliberadamente emergente. As reorientações estratégicas ou pontos de ruptura não fizeram parte de forma expressiva da trajetória da empresa: sua evolução ocorreu de modo gradual e pouco traumático. Continuamente, foi ressaltada a importância do planejamento estratégico pelos entrevistados. Ficou claro que, se assim não fosse, se não houvesse as deliberações, eles teriam a sensação de que a empresa caminhava sem direção e agia de forma pouco competente. Desse modo, as estratégias foram, em sua maioria, formuladas, mesmo que nem todas tenham sido realizadas, enquanto o principal fator moderador do processo de formação de estratégias foram as contingências do ambiente externo. Diante desse cenário, a empresa apresentou disposição para aprender, o que possibilitou o surgimento das estratégias emergentes.

Quanto à internacionalização da região do submédio do São Francisco (lembrando que compreendê-la auxilia a atingir o objetivo proposto neste artigo), foi observado que três correntes distintas, porém congruentes, ocorreram para que esse cluster da fruticultura alcançasse destaque internacional e o padrão de qualidade requerido pelo mercado, a saber:

1. a dinâmica da competição mundial e as janelas comerciais de exportação bem delineadas;

2. a iniciativa empresarial altamente profissionalizada; $\mathrm{e}$

3. os investimentos públicos na irrigação, representados pela Codevasf, que impulsionaram sobremaneira os resultados do pólo.

Os fatores de produção presentes no ambiente externo (quais sejam: água irrigada e clima favorável) foram decisivos para que o grupo buscasse sua identidade como produtor e exportador de manga. A própria decisão pela internacionalização foi sobreposta pelas variáveis contextuais.

Esta é, portanto, mais uma característica do processo de formação de estratégias internacionais do grupo no período entre 1982 e 1985: não é possível desassociá-lo do desenvolvimento da região, das condições climáticas e do apoio dos parceiros correlatos. Entender o papel exercido pela Codevasf no submédio foi o ponto de partida para a análise desse processo. Daí a intensidade da dimensão "contexto" para o fenômeno investigado. Esse argumento foi ainda mais evidente nos primeiros anos; nos seguintes, deixaram de ser decisivos e fontes de vantagem competitiva para assumirem a posição sine qua non, em que demais variáveis como recursos competitivos idiossincráticos e redes de relacionamento pessoais ditaram as regras da competição. $\mathrm{O}$ argumento de que o contexto externo tenha sido predominante no início das operações internacionais do grupo é corroborado ainda pelo extremo oportunismo verificado entre 1982 e 1993.

Por essas razões, é possível observar também que, sendo possível estabelecer uma ordem hierárquica de influência no sucesso (não só do Grupo Fruitfort, mas das demais empresas de grande porte que formam o submédio do São Francisco, assumindo que seu padrão de competição é bastante próximo entre si), tal ordem se estabeleceria na seguinte dinâmica: alta influência do ambiente externo e baixa influência do ambiente interno, nas duas primeiras fases, para alta influência de ambos os ambientes, nas terceira e quarta. As principais dimensões e fases podem ser observadas no framework apresentado da figura 2, onde destacam-se os conceitos-chave das teorias de internacionalização empiricamente analisados na trajetória da Fruitfort, de acordo com as dimensões de Pettigrew (1987). 
A descrição das fases e dos eventos que compuseram a trajetória do Grupo Fruitfort evidencia que o fenômeno investigado apresenta características multifacetadas, daí a dificuldade de entendê-lo plenamente se adotarmos apenas uma perspectiva teórica de internacionalização e se desconsiderarmos a ótica contextualista-processual de Pettigrew $(1985,1987)$.

Corroborando o argumento desenvolvido até aqui, tem-se que o contexto foi predominante nas fases um, três e quatro, embora as três dimensões da mudança se fizessem presentes em todos os momentos. Na primeira fase, o processo e o conteúdo sucumbiram às variáveis contextuais. A segunda foi marcada por um período de gradualismo e de continuidade. Na terceira, a implantação do Plano Real e a percepção do gap na janela norteamericana ditaram as regras para a necessidade da reestruturação orgânica vivenciada e para o início das exportações aos EUA. A quarta e última fase foi caracterizada pela necessidade de investimento no profissionalismo e no aumento da produtividade.

Por fim, uma ligação pertinente entre modelos de internacionalização e as tipologias de estratégia empresarial quais sejam, deliberadas e emergentes - permite inferir que as características do processo de formação de estratégias internacional do grupo tiveram em seu componente deliberado questões referentes ao modelo Diamante e às vantagens de localização. Permite igualmente deduzir que seu componente emergente foi constituído da aprendizagem incremental proposta pela Escola de Uppsala. A liderança e a cultura organizacional, como recursos competitivos idiossincráticos, permitiram que fosse estabelecido um equilíbrio entre essas duas perspectivas, dotando o processo de um caráter deliberadamente emergente. 


\section{Referências}

ANDERSSON, U.; JOHANSON, J., VAHLNE, J. Organic acquisitions in the internationalization process of the business firm. Management International Review, v.37. n.2, p.67-84, 1997.

BARNEY, J. Firm resources and sustained competitive advantage. Journal of Management, v.17, n.1, p.99-120, 1991.

. Gaining and sustaining competitive advantage. New Jersey: Prentice Hall, 2002.

BRASIL - Ministério do Desenvolvimento. Disponível em <www.mdic.gov.br>. Acesso em 19 jan. 2006 e 3 fev. 2007.

BRAZILIAN FRUIT. Disponível em:<www.brazilianfruit.org>. Acesso em: 29 mar. 2006.

CHANDLER, A. Organizational capabilities and the economic history of the international enterprise. Journal of Economic Perspectives, v.6, n.3, p.79-100, 1992.

CHILD, John. Organizational structure, environment and performance: the role of strategic choice. Sociology, v.6, n.1, 1972.

CORREIA; R. C.; ARAÚJO, J. L. P.; CAVALCANTI, E. B. A fruticultura como vetor de desenvolvimento: o caso dos municípios de Petrolina (PE) e Juazeiro (BA). [S.I.]: [s.n.], 2001.

DHANARAJ, Charles; BEAMISH, Paul W. A resource-based approach to the study of export performance. Journal of Small Business Management, v.41, n.3, p.242-261, 2003.

DUNNING, J. H. Towards an eclectic theory of international production: some empirical tests. Journal of International Business Studies, v.11, n.1, p.9-31, 1980.

The eclectic paradigm of international production: a restatement and some possible extensions. Journal of International Business Studies, v.19, n.1, p.1-31, 1988.

FAHY, John. Resources and global competitive advantage: a study of the automotive components industry in Ireland. Irish Marketing Review, v.10, n.2, 1998.

FERNANDES, M. G., ROCHA, A. Measuring the psychic distance construct: a test of two data collection instruments. In: XXIX Encontro Anual da Associação Nacional dos Programas de Pós-Graduação em Administração, Anais..., Brasília: ANPAD, 2005.

FRANCISCO, João Manuel Saveia Daniel. Internacionalização para um mercado culturalmente próximo, mas em guerra: a Odebrecht em Angola. In. ENCONTRO ANUAL DA ASSOCIAÇÃO NACIONAL DOS PROGRAMAS DE PÓS-GRADUAÇÃO EM ADMINISTRAÇÃO, 28., 2004, Curitiba. Anais... Rio de Janeiro: Anpad, 2004.

FRUITFORT. Disponível em: <www.fruitfort.com.br>. Acesso em 27 jan. 2006 e 16 mar. 2006.

GOMES, Romeu. A análise de dados em pesquisa qualitativa. In: MINAYO, M. C. S. (Org.). Pesquisa social: teoria, método e criatividade. 23.ed. Petrópolis: Vozes, 2004.

GRANT, R. M. The resource-based theory of competitive advantage: implications for strategy formulation. California Management Review, v.33, n.3, p.114-135, Spring 1991.

HEMAIS, Carlos A., HILAL, Adriana. O processo de internacionalização da firma segundo a Escola Nórdica. In: ROCHA, Ângela da. A internacionalização das empresas brasileiras: estudos de gestão internacional. 1.ed. Rio de Janeiro: Mauad, 2002.

IBRAF. Instituto Brasileiro de Frutas. Disponível em: <www.ibraf.org.br>. Acesso em: 19 jan. 2006 e 29 mar. 2007.

JOHANSON, J.; VAHLNE, Jan-Erik. The internationalization process of the firm: a model of knowledge development and increasing foreign markets commitments. Journal of International Business Studies, p.23-32, spring 1977.

. The mechanism of the internationalisation. International Marketing Review, p.11-24, 1997.

; WIEDERSHEIM-PAUL, F. The internationalization of the firm: four Swedish cases. The Journal of Management Studies, p.305-322, Oct. 1975. 
LAM, Long W; WHITE, Louis P. An adaptative choice model of the internationalization process. International Journal of Organizational Analysis, v.7, n.2, p.105-134, April 1999.

MALHOTRA, N. K. Pesquisa de marketing: uma orientação aplicada. Porto Alegre: Bookman, 2004.

MATOS; K. S. L.; VIEIRA, S. L. Pesquisa educacional: o prazer de conhecer. Fortaleza: Uece, 2001.

MELIN, L. Internationalization as a strategy process. Strategic Management Journal, v.13, p.99-118, 1992.

MERRIAM, S. B. Qualitative research and case study applications in education. San Francisco: Jossey-Bass, 1998.

MINTZBERG, Henry. A criação artesanal da estratégia. In: MONTGOMERY, C.; PORTER, M. Estratégia: a busca da vantagem competitiva. 2.ed. Rio de Janeiro: Campus, 1998. p.419-437.

; AHLSTRAND, Bruce; LAMPEL, Joseph. Safári de estratégia: um roteiro pela selva do planejamento estratégico. Porto Alegre: Bookman, 2000.

PATTON, M. Qualitative research and evaluation methods. $3^{\text {rd }}$ ed. Thousand Oaks: Sage, 2001.

PENROSE, Edith. Teoria del crescimiento de la empresa. Madri: Aguilar, 1962.

PETERAF, M. A. The cornerstones of competitive advantage: a resource-based view. Strategic Management Journal, v.14, n.3, p.179-188, 1993.

PETTIGREW, A. M. Contextualist research: a natural way to link theory and practice. In: LAWLER, E. Doing research that is useful in theory and practice. San Francisco: Jossey-Bass, 1985. Nov. 1987.

Context and action in transformation of the firm. Journal of Management Studies, v.24, n.6, p.649-670,

PORTER, M. E. Estratégia competitiva: técnicas para análise da indústria e da concorrência. Rio de Janeiro: Campus, 1986.

Vantagem competitiva das nações. Rio de Janeiro: Campus, 1989.

. Toward a dynamic theory of strategy. Strategic Management Journal, v.12, p.95-117, Winter issue 1991.

. Vantagem competitiva das nações. Em: PORTER, M. E. Competição: estratégias competitivas essenciais. Rio de Janeiro: Campus, 1999.

QUINN, J. B. Strategic change: logical incrementalism. Sloan Management Review, p.7-21, Fall 1978.

ROESCH, Sylvia Maria Azevedo. Projetos de estágio e pesquisa em administração. 2.ed. São Paulo: Atlas, 1999.

SHARMA, Varinder M.; ERRAMILLI, M. Krishna. Resource-based explanation of entry mode choice. Journal of Marketing Theory and Practice, v.12, n.1, p.1-18, Winter 2004.

STAKE, Robert E. The case of case study research. Thousand Oaks: Sage Publications, 1995. p.1-12.

VALEXPORT. Disponível: <http://www.valexport.com.br>. Acesso em 10 jan. 2006 e 27 jan. 2007).

VAN DE VEN, Andrew H. Suggestions for studying strategy process: a research note. Strategic Management Journal, v.13, p.169-188, 1992.

VERNON, Raymond. International investment and international trade in the product cycle. Quarterly Journal of Economics, v.80, n., p.191-207, 1966.

. The product cycle hypothesis in a new international environment. Bulletin, p.255-267, 1969.

WELCH, Lawrence S.; LUOSTARINEN, Reijo. Internacionalization: evolution of a concept. Journal of General Management, v.14, n.2, p.34-55, 1988.

WERNERFELT, B. A resource-based view of the firm. Strategic Management Journal, v.5, p.171-180, 1984.

WYZYKOWSKI, J.; ARAÚJO, J. L. P.; ALMEIDA, C. O. Mercado e comercialização. In: ARAÚJO, J. L. P. Manga, cap.19, p.432-444, 2002. 
Brigitte Renata Bezerra de Oliveira Walter Fernando Araújo de Moraes

Processo de formação de estratégias internacionais na Érica Piros Kovacs fruticultura brasileira: uma abordagem integrada Rafael Lucian

XAVIER, C. L.; VIANA, F. D. F. Inserção externa e competitividade dos estados da região Nordeste do Brasil no período 1995-2004. Revista Econômica do Nordeste, v.36, n.3, p.456-469, jul./set. 2005.

YIN, Robert K. Estudo de caso: planejamento e métodos. 2.ed. Porto Alegre: Brookman, 2001. 